\title{
Role of allostatic load and health behaviours in explaining socioeconomic disparities in mortality: a structural equation modeling approach.
}

Gyu Ri Kim ${ }^{1}$ Sun Ha Jee ${ }^{2}$ Hynek Pikhart ${ }^{3}$

${ }^{1}$ Department of Biostatistics, Graduate School of Public Health, Yonsei University, Seoul, Korea.

2 Department of Epidemiology and Health Promotion and Institute of Health Promotion, Graduate School of Public Health, Yonsei University, Seoul, Korea.

${ }^{3}$ Department of Epidemiology and Public Health, University College London, London, UK.

GRK Email: gyurikim@yuhs.ac Tel: +82 222281519

SHJ Email: jsunha@yuhs.ac Tel: +82 222281523

HP Email: h.pikhart@ucl.ac.uk Tel: +44 2078130280

Corresponding author: Sun Ha Jee,

Email: jsunha@yuhs.ac

Department of Epidemiology and Health Promotion and Institute of Health Promotion, Graduate School of Public Health, Yonsei University, 50-1 Yonsei-ro, Seodaemun-gu, Seoul, 50-1, Korea

Tel: +82 222281523

Word count: 4,814

Tables: 3 Figures: 2 


\section{Abstract}

2 BACKGROUND: The relationship between socioeconomic status and mortality has been 3 well established, however, the extent to which biological factors mediate this relationship is 4 less clear and empirical evidence from non-Western settings is limited. Allostasis, a 5 cumulative measure of physiological dysregulation, has been proposed as the underlying 6 mechanism linking socioeconomic status to adverse health outcomes. The current study 7 aimed to ascertain the contribution of allostatic load and health behaviours to socioeconomic 8 inequalities in mortality among Korean adults.

9 METHODS: The sample comprised 70,713 middle and older aged adults, aged 40-79 years from the Korean Metabolic Syndrome Mortality Study. Using structural equation modeling, mediation analyses were performed to estimate the effects of socioeconomic position (SEP) on mortality over the follow-up and the extent to which allostatic load, physical exercise, and non-smoking status mediate the association between SEP and mortality.

RESULTS: A total of 5,618 deaths (7.9\%) occurred during the mean follow-up of 15.2 years (standard deviation 2.9). Structural equation modeling confirmed a direct significant effect of socioeconomic position on mortality, as well as significant indirect paths through allostatic load, physical exercise, and non-smoking status.

CONCLUSIONS: Our findings provide support for the mediating role of allostatic load and health behaviours in the link between SEP and mortality. Policies designed to reduce social disparities in mortality in the long term should primarily focus on reducing stress and promoting healthy lifestyles among the socially disadvantaged groups. Future studies should further assess the role of other mediators such as psychosocial factors, which may contribute to socioeconomic inequalities in mortality.

25Keywords: Socioeconomic inequalities, Mortality, Structural Equation Modeling, Allostatic load, 26Biomarkers, Stress, Health behaviour 


\section{What is already known on this subject?}

- Socioeconomic position has consistently been found to be a strong predictor of adverse health outcomes.

- There is growing evidence that allostatic load $(A L)$, a measure of cumulative physiological dysregulation, is socially patterned, with higher $A L$ associated with lower socioeconomic position.

\section{What this study adds?}

- Allostatic load and behavioural risk factors partially explain the socioeconomic gradient in mortality among Korean adults.

- The findings of our study highlight the importance of managing stress and promoting healthy lifestyles as the means to reduce social inequalities in mortality. 


\section{Introduction}

2 Socio-economic position (SEP), whether defined by income, education or occupation, has

3 consistently been associated with a wide range of adverse health outcomes, including 4 cardiovascular disease[1], cancer[2], and mortality.[3, 4] Empirical studies seeking to identify 5 the mechanisms that account for the relationships between SEP and mortality have suggested 6 that psychosocial factors[5] and behavioural risk factors, namely smoking, physical inactivity, 7 and alcohol consumption have important roles in explaining socioeconomic disparities in 8 health.[6, 7] However, the extent to which biological risk factors mediate this relationship 9 remains unclear.

Despite mounting evidence that lower SEP is associated with a range of biological risk factors, including impaired glucose tolerance, insulin resistance[8], elevated levels of cortisol[9], interleukin-6[10], and C-reactive protein[10], few studies to date have explored the potential mediating effects of biomarkers and allostatic load in explaining socioeconomic disparities in health, and the results have been mixed.[9, 11, 12] Allostatic load refers to the cumulative stress-related wear and tear on the multiple physiological system, representing neuroendocrine, immune, cardiovascular, and metabolic functioning.[13] Using data from the MacArthur Study, Seeman et al have identified that lower SEP is associated with increased allostatic load $(A L)$, and that $A L$ mediates the relationship between SEP and mortality, explaining around $35 \%$ of the difference in mortality attributable to educational differences.[14] Similarly, another study found that biological risk factors explained $19 \%$ of the educational differences in general health.[15] In contrast to these findings, an analysis based on the Taiwanese social environment and biomarkers of aging study failed to find support for the mediating role of AL biomarkers in explaining the social gradient in health.[12] Two previous studies conducted in South Korea found that biological and health behaviours contributed only a very small fraction to the reduction of excess mortality risk for those in the low income groups[3,16].

Building on this empirical evidence, we examined two major research questions. First, we aimed to assess whether socioeconomic position, as measured by occupational, household income, and education level is associated with all-cause mortality, in a large cohort of adults living in Korea. Second, we tested the underlying pathways through which socioeconomic position influence mortality. Specifically, we tested the hypothesis that relationship between 
1 socioeconomic position and mortality is partially mediated by allostatic load and health

2 behaviours using structural equation modeling (see Figure 1).

6 Methods

\section{$7 \quad$ Data and Study Population}

8 The Korean Metabolic Syndrome Mortality Study (KMSMS) is a retrospective cohort study
<Figure 1 about here> based on data from private health examinations conducted at 18 centers in South Korea. Of these centers, 14 centers provided informed consent and were selected for our study. Additional details of the study have been reported elsewhere[17]. Between 1994 and 2004, a total of 560,643 men and women aged 20 years or older, attended a health assessment for a comprehensive physical assessment. The analytic sample was restricted to participants aged 40 and older than 79 years old, and those who had complete information on mortality and each socioeconomic position indicator $(\mathrm{N}=74,883)$. Additionally, individuals taking medications for diabetes, hypertension, or high blood cholesterol and those who died within 1 year of follow-up were excluded $(\mathrm{N}=4,170)$. Thus, the final sample consisted of 70,713 participants (43,232 men and 27,481 women). All participants provided written informed consent to participate and ethical approval for the study was obtained from the Institutional Review Board for Human Research at Yonsei University and all individual health promotion centers participating in the KMSMS.

\section{Measurements}

\section{Mortality follow-up}

The vital study of study participants was identified through data linkage with nationwide death report data from the South Korean National Statistical Office, using the unique personal identification number assigned to all persons residing in South Korea. All individuals were followed from the baseline examination (between 1994 to 2004) to the date of their death or otherwise until the censoring date of 31 December 2014. 
2 Socioeconomic position was estimated as a latent variable comprising educational level, occupation, and monthly household income. Level of education was categorized as primary school or lower ( $\leq 6$ years), middle school (7 to 9 years), high school (10 to 12 years), and university and higher ( $\geq 13$ years) according to the number of years of school attendance. Monthly household income was divided into quartiles and categorized as low (quartile 1 or Q1), medium-low (Q2), medium-high (Q3), and high (Q4) according to the monthly household equivalent income. Additionally, occupation was collapsed into six categories: 1) Unemployed (including housewives and students) 2) Simple labour, manufacturing 3) Agriculture, forestry, fishery workers

4) Service and sales workers

5) Clerks

6) Professional/managerial workers. These variables were declared categorical in Mplus.

\section{Allostatic Load (AL)}

In the current study, operationalization of $A L$ was based on both previous research and data availability [18-20]. Seven biomarkers were available in the KMSMS for constructing the allostatic load score: systolic/diastolic blood pressure, and pulse rate reflecting cardiovascular activity; glycated hemoglobin $\left(\mathrm{HbA}_{1 \mathrm{c}}\right)$, high-density lipoprotein ( $\left.\mathrm{HDL}\right)$ and total cholesterol representing metabolic system and albumin reflecting inflammation. Blood pressure was measured by registered nurses or technicians using a standard mercury sphygmomanometer. In the case of systolic and diastolic blood pressure, two measurements were taken with five minute gap between two measurements and an average of the two readings was recorded. Glycated hemoglobin $\mathrm{HbA} 1 \mathrm{c}$, total cholesterol and HDL-cholesterol were measured from fasting samples. In line with previous research, [21 22] for each of seven biomarkers, participants in the high-risk quartile distribution were given a score of 1 ; the others were given a score of 0 . For most AL-related biomarkers, values above the $75^{\text {th }}$ percentile were defined as high-risk. However, for albumin and high-density lipoprotein cholesterol, high-risk values were those in the bottom $25 \%$ of the distribution. Scores for each biomarker were then summed to create an overall $A L$ score ranging from 0 to 7 . In this sample of adults, high-risk thresholds were as follows: Diastolic blood pressure, $84 \mathrm{~mm} \mathrm{Hg}$; systolic blood pressure, 139 $\mathrm{mm} \mathrm{Hg}$; Pulse, 65 beats/min; glycated hemoglobin, 5.5\%; total cholesterol, $222 \mathrm{mg} / \mathrm{dL}$, albumin, $4.4 \mathrm{~g} / \mathrm{dL}$. Each center had internal and external quality control procedures as required by the Korean Association of Laboratory Quality Control, and each biomedical marker 
demonstrated high correlation across individual centers, with correlation coefficient ranging

2 from 0.96 to 0.99 .

3

\section{Health Behaviours}

\section{$5 \quad$ Non-Smoking}

6 Participants were divided into never-, former, and current smokers based on their choice of 7 three possible responses to the following question, "Do you currently smoke cigarettes?"

8 Participants who answered "no" were classified as "never-smokers," those who answered "yes, 9 but I quit smoking" were classified as "former smokers," and those answered "yes, and I 10 currently smoke" were classified as "current smokers." For the purpose of our analysis, we 11 further dichotomized smoking status into current smokers and non-smokers (never and former 12 smokers).

\section{Physical exercise}

At baseline, participants were asked report if they engage in regular exercise with the question, "Do you do regular exercise?", and coded as $1=$ No; $2=$ Yes.

\section{Covariates}

Several variables that are known to affect mortality were included in the model as controls: Age was assessed as a continuous variable, sex was coded as male (reference) and female. Marital status was coded as follows: $1=$ single, including never married, divorced, separated or widowed (reference); $2=$ married. Body mass index (BMI) was measured on continuous scale, and was calculated from measured height and weight using the formula $\mathrm{kg} / \mathrm{m}^{2}$. Measurements were taken of participants dressed in light clothing.

\section{Statistical analysis}

Stata version 13 was used for preliminary analyses, and Mplus version 7.4 was used for the structural equation modeling analyses [23]. Initially, descriptive statistics were computed for the non-imputed dataset. This included frequencies and percentages for categorical variables and means and standard deviation for continuous variables. Differences in baseline 
characteristics among deceased and alive participants were compared using the likelihoodratio test (G-test) for categorical variables and t-tests for continuously scaled variables. Spearman's correlation coefficients were computed to investigate bivariate associations among the variables used in this study. Socio-demographic and behavioral variables showing a statistically significant relationship $(p \leq 0.05)$ with socioeconomic position variables or allcause mortality in preliminary analysis were then included in structural equation models for mediation analyses.

Subsequently, proportional hazards in a structural equation modeling framework was used to evaluate mediating pathways that may play a role in the link between socioeconomic position and mortality.[24] A complete case approach in proportional hazards regression models has been shown to be inappropriate when data are not missing at random.[25] To reduce potential bias caused by missing data, we used multiple imputation procedure with 20 imputations to complete-case dataset produced largely concordant results with those from imputed models (Table S1). The SEM analysis proceeded in two stages: 1) Confirmatory factor analysis of SEP latent variable was conducted to evaluate the model fit using a robust weighted least squares (WLSMV) estimation implemented in MPlus. Evaluation of model fit was determined by the following indices: Comparative Fit Index (CFI), the Tucker-Lewis Index (TLI) and the root mean square error of approximation (RMSEA). A value of CFI $\geq 0.95$, TLI $\geq 0.95$, and RMSEA $<0.06$ were considered indicative of good model fit.[26] 2) the full hypothesized structural relationships between variables were tested as shown in Figure 2. We estimated direct effects of SEP on mortality risk, and indirect effects were investigated to further test the mediating role of allostatic load, smoking status and physical exercise in the relationship between SEP and mortality. Indirect effects were calculated by multiplying the two parameters involved in the mediation.[27] For example, to obtain the effect of SEP on mortality through the allostatic load, the raw coefficients for the effect of SEP on AL (Path a) was multiplied by the effect of $A L$ on mortality (Path b). The regression coefficients were exponentiated to obtain hazard ratios (HRs). The total effect of SEP on the outcome was computed by adding the direct and indirect effects of the exogenous variable on the outcome. The proportion mediated (for each individual mediator and for all mediators combined) was determined by dividing the indirect effect by the total effect. The maximum likelihood (MLR) estimator was used to produce parameter estimates and standard errors that were robust to non-normality as the allostatic load variable had small degrees of skewness and kurtosis. All reported $P$ values were two- 
2

3

4

5

6

sided and statistical significance was set at 0.05 .

\section{Results}

\section{Sample characteristics}

Descriptive statistics of the non-imputed sample are presented in Table 1 for the whole sample and by vital status. A total of 5,618 deaths $(7.9 \%)$ occurred during the follow-up period and the mean length of follow-up was 15.2 years (standard deviation 2.9). In the overall sample, mean age was 50.9 years (Standard deviation 7.7 ) with $61.1 \%$ being male. $33.8 \%$ of the participants attained university level qualifications, $32.8 \%$ completed high school, $17.2 \%$ had middle school education, while $16.2 \%$ of the participants had no formal education or completed only up to primary level. Reported monthly household income ranged from less than or equal to $1,500,000$ Korean Won (KRW) (37.4\%) to more than 4,000,000 KRW (15.2\%), with $\leq 1,500,000$ KRW being the most frequently endorsed income range, followed by $2,000,000-3,000,000$ KRW (33.5\%). Most of the participants were married (91.3\%); $7.5 \%$ were single (either never married, divorced, widowed or separated). There were 46,866 (66.3\%) non-smokers, and $22,834(32.3 \%)$ current smokers. $44.7 \%$ of participants reported engaging in regular physical exercise.

Deceased persons were older and had a higher percentage of men than surviving study participants. The mean allostatic load score was higher among deceased than survivors (2.3 vs. 1.9; $p<0.001)$. Further, there were statistically significant differences between deceased and alive participants in terms of smoking status $(42.6 \%$ current smokers in the deceased group compared to $31.4 \%$ in the alive group; $p<0.001)$ and physical exercise $(45.2 \%$ of alive participants engage in regular physical exercise compared to $39.6 \%$ in the deceased group). The effect of alcohol consumption was tested in a preliminary analysis and found to be nonsignificant, therefore were not considered further for the present analysis. 
Table 1 Socio-demographic and behavioural characteristics of deceased and surviving participants in KMSMS.

\begin{tabular}{|c|c|c|c|c|c|}
\hline Variables $^{a}$ & & $\begin{array}{l}\text { Total } \\
\mathrm{N}=70,713(\%)\end{array}$ & $\begin{array}{c}\text { Alive } \\
\text { N (\%) } \\
\end{array}$ & $\begin{array}{c}\text { Deceased } \\
\mathrm{N}(\%) \\
\end{array}$ & P-value ${ }^{b}$ \\
\hline \multirow{4}{*}{$\begin{array}{l}\text { All } \\
\text { Age (mean, SD) } \\
\text { Gender }\end{array}$} & & & $65,095(92.1)$ & $5,618(7.9)$ & \\
\hline & & $50.9(7.7)$ & $50.3(7.3)$ & $50.9(7.7)$ & $<0.001$ \\
\hline & Male & $43,232(61.1)$ & $39,113(60.1)$ & 4,119 (73.3) & $<0.001$ \\
\hline & Female & $27,481(38.9)$ & $25,982(39.9)$ & $1,499(26.7)$ & \\
\hline \multirow[t]{4}{*}{ Income level (Unit:10,000won) } & Q1 ( $\leq 150)$ & $26,433(37.4)$ & $23,634(36.3)$ & $2,799(49.8)$ & $<0.001$ \\
\hline & Q2 (200-300) & $23,699(33.5)$ & $22,042(33.9)$ & $1,657(29.5)$ & \\
\hline & Q3 (350-400) & $9,811(13.9)$ & $9,165(14.1)$ & $646(11.5)$ & \\
\hline & Q4 $(>400)$ & $10,770(15.2)$ & $10,254(15.7)$ & $516(9.2)$ & \\
\hline \multirow[t]{4}{*}{ Education level } & No formal education or upto primary level ( $\leq 6$ years) & $11,442(16.2)$ & $9,906(15.2)$ & $1,536(27.3)$ & $<0.001$ \\
\hline & Middle school (7-9 years) & $12,187(17.2)$ & $11,056(17.0)$ & $1,131(20.1)$ & \\
\hline & High school (10-12 years) & 23,217 (32.8) & 21,671 (33.3) & $1,546(27.5)$ & \\
\hline & University or above ( $\geq 13$ years) & $23,867(33.8)$ & $22,462(34.5)$ & $1,405(25.1)$ & \\
\hline \multirow[t]{6}{*}{ Occupational status } & Unemployed & $22,946(32.5)$ & $21,110(32.4)$ & $1,836(32.7)$ & $<0.001$ \\
\hline & Simple labour/manufacturing & $11,937(16.9)$ & $11,028(16.9)$ & $909(16.2)$ & \\
\hline & Agriculture/Forestry/Fishery & $3,620(5.12)$ & $2,994(4.6)$ & $626(11.1)$ & \\
\hline & Service and sales workers & $11,442(16.2)$ & $10,556(16.2)$ & $886(15.8)$ & \\
\hline & Clerical & $12,058(17.0)$ & $11,292(17.4)$ & 766 (13.6) & \\
\hline & Professional \& managerial position & $8,710(12.3)$ & $8,115(12.5)$ & $595(10.6)$ & \\
\hline \multirow[t]{3}{*}{ Marital status } & Single (Never married, divorced, separated, widowed) & $5,274(7.5)$ & $4,730(7.3)$ & $544(9.7)$ & $<0.001$ \\
\hline & Married & $64,619(91.3)$ & $59,644(91.6)$ & $4,975(88.6)$ & \\
\hline & Missing & $820(1.2)$ & $721(1.1)$ & $99(1.7)$ & \\
\hline \multicolumn{6}{|l|}{ Smoking status } \\
\hline & Current smoker & $22,834(32.3)$ & $20,441(31.4)$ & $2,393(42.6)$ & $<0.001$ \\
\hline & Non-smoker & $46,866(66.3)$ & $43,718(67.2)$ & $3,148(56.0)$ & \\
\hline & Missing & $1,013(1.4)$ & $936(1.4)$ & $77(1.4)$ & \\
\hline \multirow[t]{4}{*}{ Physical exercise } & & & & & $<0.001$ \\
\hline & No & $36,470(51.6)$ & 33,259 (51.1) & $3,211(57.2)$ & \\
\hline & Yes & $31,630(44.7)$ & 29,405 (45.2) & 2,225 (39.6) & \\
\hline & Missing & $2,613(3.7)$ & $2,431(3.7)$ & $182(3.2)$ & \\
\hline \multirow[t]{2}{*}{ Allostatic load $\quad(0-7$; continuous $)$} & Mean (SD) & $1.96(1.2)$ & $1.9(1.2)$ & $2.3(1.3)$ & $<0.001$ \\
\hline & Missing & 52,507 (74.3) & & & \\
\hline
\end{tabular}

a Data are presented as means ( \pm SD) for continuous variables and percentage for categorical variables.

b $\mathrm{P}$-values from $\mathrm{T}$ - tests for continuous variables and likelihood-ratio tests (G-test) for categorical variables. 
2 As can be seen in Table 2, there were generally small to moderate correlations between study 3 variables. Allostatic load $(A L)$ had small but significant inverse correlation with education $(r=-$ 4 0.11), household income $(r=-0.15)$ and occupation $(r=-0.04)$; all $p$ 5 values $<0.001$ by Spearman's rank. A significant positive relationship was identified between 6 AL and all-cause mortality ( $r=0.07)$. The Spearman's rank correlation test showed that physical 7 exercise is positively correlated with education $(r=0.02)$, household income $(r=0.14)$, 8 occupation $(r=0.10)$ and inversely correlated with mortality $(r=-0.02)$. Non-smoking status significantly negatively correlated with occupation $(r=-0.09)$ and mortality $(r=-0.05)$, while education $(r=0.02)$ and household income $(r=0.14)$ were positively correlated with nonsmoking status.

Table 2 Spearman's rank correlation among study variables

\begin{tabular}{|c|c|c|c|c|c|c|c|c|c|c|}
\hline & 1 & 2 & 3 & 4 & 5 & 6 & 7 & 8 & 9 & 10 \\
\hline 1. Age & 1 & & & & & & & & & \\
\hline 2. Gender & $0.12^{* * *}$ & 1 & & & & & & & & \\
\hline 3. Marital status & $-0.05^{\star \star \star}$ & $-0.12^{* \star \star}$ & 1 & & & & & & & \\
\hline 4. Education & $-0.26^{\star \star \star}$ & $-0.15^{* * *}$ & $0.17^{* * *}$ & 1 & & & & & & \\
\hline $\begin{array}{l}\text { 5. Household } \\
\text { income }\end{array}$ & $-0.06^{\star \star \star}$ & $0.12^{* \star *}$ & $0.13^{* * *}$ & $0.59^{* * *}$ & 1 & & & & & \\
\hline 6. Occupation & $-0.18^{\star * *}$ & $-0.39^{* * *}$ & $0.08^{\star \star *}$ & $0.48^{* * *}$ & $0.34^{\star * *}$ & 1 & & & & \\
\hline $\begin{array}{l}\text { 7. Non-smoking } \\
\text { status }\end{array}$ & $0.10^{* * *}$ & $0.38^{* * *}$ & 0.01 & $0.02^{*}$ & $0.14^{* \star \star}$ & $-0.09^{\star * *}$ & 1 & & & \\
\hline $\begin{array}{l}\text { 8. Physical } \\
\text { exercise }\end{array}$ & $-0.02^{* *}$ & $-0.14^{* * *}$ & $0.04^{\star \star \star}$ & $0.19^{* * *}$ & $0.08^{* * *}$ & $0.10^{\star \star \star}$ & $0.04^{* * \star}$ & 1 & & \\
\hline 9. Mortality & $0.17^{\star * \star}$ & $-0.03^{\star \star *}$ & $-0.04^{* \star *}$ & $-0.09^{* \star *}$ & $-0.05^{* * *}$ & $-0.03^{* \star *}$ & $-0.05^{* * *}$ & $0.02^{\star *}$ & 1 & \\
\hline $\begin{array}{l}\text { 10. Allostatic } \\
\text { load }\end{array}$ & $0.11^{* * *}$ & $-0.06^{* * *}$ & $-0.06^{* * *}$ & $-0.11^{* * *}$ & $-0.15^{\star \star \star}$ & $-0.04^{* * *}$ & $-0.02^{*}$ & 0.04 & $0.07^{* \star *}$ & 1 \\
\hline
\end{tabular}




\section{$1 \quad$ Structural Equation Modeling}

\section{Evaluation of Measurement Model and Mediation Analyses}

3 Confirmatory factor analysis was used to test the measurement properties of the latent

4 variable for socioeconomic position using three variables (education, household income, and 5 occupation). The results indicated that all factor indicators were significantly loaded on the 6 corresponding SEP latent construct. The standardized loadings ranged from 0.45 to 0.97 , with 7 all significant at the $<0.001$ level. The fit of measurement model was excellent $(C F I=1.00$, $8 \mathrm{TLI}=1.00, \mathrm{RMSEA}<0.01$ ), with $\mathrm{CFI}$ and $\mathrm{TLI}$ values greater than 0.95 and RMSEA smaller than 90.06 . 
Table 3 Total, Direct and Indirect Effects of Socioeconomic Position on All-cause Mortality Mediated Through Allostatic Load and Health Behaviours.

\begin{tabular}{|c|c|c|c|}
\hline & Regression coefficient (S.E) & $\begin{array}{l}\text { Hazard ratio ( } 95 \% \\
\text { confidence interval) }\end{array}$ & p-value \\
\hline \multicolumn{4}{|l|}{ Direct effect } \\
\hline SEP $\rightarrow$ Mortality & $-0.247(0.018)$ & 0.781 (0.758 to 0.804$)$ & $P<0.001$ \\
\hline \multicolumn{4}{|l|}{ Indirect effects } \\
\hline $\mathrm{SEP} \rightarrow \mathrm{AL} \rightarrow$ Mortality & $-0.020(0.004)$ & 0.980 (0.973 to 0.987$)$ & $P<0.001$ \\
\hline $\mathrm{SEP} \rightarrow$ Non-smoking status $\rightarrow$ Mortality & $-0.022(0.002)$ & $0.978(0.975$ to 0.981$)$ & $P<0.001$ \\
\hline $\mathrm{SEP} \rightarrow$ Physical exercise $\rightarrow$ Mortality & $-0.015(0.003)$ & 0.985 (0.980 to 0.990$)$ & $P<0.001$ \\
\hline $\begin{array}{l}\text { Total effect of SEP on Mortality } \\
\text { (Sum of indirect effects and direct effect) }\end{array}$ & $-0.304(0.016)$ & 0.738 (0.718 to 0.758$)$ & $P<0.001$ \\
\hline \multicolumn{4}{|c|}{ Proportion of the effect of SES on Mortality that was : } \\
\hline Mediated by AL (\%) & 6.6 & & \\
\hline Mediated by non-smoking (\%) & 7.2 & & \\
\hline Mediated by physical exercise (\%) & 4.9 & & \\
\hline Total indirect effect (\%) & 18.7 & & \\
\hline Direct effect (\%) & 81.3 & & \\
\hline
\end{tabular}

a Standard error

Note: SEP=Socioeconomic Position; $\mathrm{AL}=$ Allostatic load; 


\section{Discussion}

2 The purpose of this study was to extend previous research on social inequalities in mortality

3 by examining the underlying pathways through which socioeconomic position is linked with

4 mortality using structural equation modeling (SEM). In contrast to the existing research, much

5 of which has been derived from Western populations, our study is based on a large cohort of

6 adults in South Korea.

8 Consistent with prior findings[28, 29], we observed a significant inverse relationship between

9 SEP and all-cause mortality. Moreover, SEP exerted an indirect effect on mortality through

10 allostatic load, such that higher SEP was associated with lower allostatic load score, which in

11 turn was associated with lower risk of death. These findings are concordant with numerous

12 prior studies that have found a significant association of $A L$ and its components with both socioeconomic position [11,30] and mortality.[31, 32]. Although not a universal finding, several studies have yielded evidence to support the mediating role of $A L$ in the link between SEP and mortality. For example, in the analysis of 1,189 initially high functioning men and women aged 70 to 79 from the MacArthur study of Successful Aging, Seeman et al.[14] have demonstrated that approximately one-third of the educational differences in mortality was mediated by the summary index of allostatic load. Another study found that biological risk accounted for a substantial portion (between 19-36\%) of social disparities in health among participants of the Survey on Stress, Aging, and Health (SAHR) in Russia.[15] A Taiwanese study showed that higher allostatic load was independent determinant of self-rated health but no explanatory factor for socioeconomic differentials in health.[33] Our study found much weaker mediating effects of $A L$ than that found in the MacArthur Study. One possible explanation for the contrasting results might be attributed to the variability in the choice of biomarkers used to represent AL. Unlike the MacArthur studies, our measure of AL did not include markers of neuroendocrine functioning. Previous studies indicated that neuroendocrine biomarkers, such as cortisol and Interleukin-6 are better predictors of mortality than metabolic biomarkers.[31, 34] Consequently, allostatic load as defined in the present study may underestimate the extent to which cumulative biological risk factors mediate socioeconomic differences in mortality.

Additionally, mediation analyses showed that SEP has modest but significant indirect effects on mortality through positive health behaviours, specifically physical exercise and nonsmoking status. Our findings are not directly comparable with previous studies because of the 
1 differences in the set of behavioural and socioeconomic measures used. However, 2 combinations of potentially modifiable behavioural risk factors (i.e smoking, alcohol 3 consumption, physical activity and diet) have been found to account for between $8 \%$ and $45 \%$ 4 of the socioeconomic differences in mortality.[3, 7] For example, in a 5-year follow-up of 5 Korean adults, Khang \& Kim concluded that smoking, alcohol consumption, and physical exercise accounted for around $8 \%$ of the income inequalities in all-cause mortality. In line with 7 this, our study revealed a rather modest mediating effect of health behaviours, and this might be ascribed to the study design. In comparing mortality over a 19.4-year period, Stringhini and colleagues reported that health behaviours assessed at baseline explained $42 \%$ of the association between socioeconomic position and all-cause mortality, while this increased to $72 \%$ when they were entered into the analysis as time-varying covariates.[7] Accordingly, future longitudinal studies using measures collected at multiple time points are recommended to increase the explanatory power of the mediating variables included in the present study. As noted earlier, only a moderate proportion of the total effect of SEP on mortality was accounted for by the proposed mediators and a substantial proportion was left unexplained in the current study. The remaining socioeconomic inequalities in mortality, after accounting for confounders and a wide range of mediators, may be partly explained by factors which we have not taken into account in the study. These include psychological factors and additional behavioral risk factors, such as dietary patterns, low perception of control, and social support, none of which were able to be investigated in our study. There is consistent evidence that diet is socially patterned and contribute substantially to socioeconomic inequities in health.[35] Based on the results of some previous studies we can speculate that negative emotions associated with low social position induce alterations in immune and neuroendocrine responses and cardiovascular function that affect health outcomes in the long term[36]. For example, low social status has been shown to be related to more chronic stressors in the form of negative life events, negative emotions and social isolation among individuals.[37, 38] In the work domain, adverse working conditions such as low job control and job overload tend to be more prevalent among individuals in low-status jobs, suggesting that psychosocial factors may act as a stress buffer against adverse health effects of low socioeconomic position. These remains an area for future research related to $\mathrm{AL}$.

Results of this study must be interpreted while considering study limitations. First, as the participants were recruited from health promotion centers via convenience sampling, the 
sample may not be entirely representative of the overall population under study. Also, the use of cross-sectional data, limited our ability to establish causality between the relationships investigated. Additional research employing repeated measurements of the exposure and the mediators is needed to assess the temporal order of association suggested by the mediation model. Further limitation includes the use of self-reported measures of health behaviours which may have introduced recall and social desirability biases. Future studies that use both self-reported and objectively measured levels of physical activity by accelerometers are recommended to ascertain the findings of the present study. Moreover, unfortunately, the sample contained insufficient numbers of cardiovascular deaths to reliably explore causespecific mortality within this population. While all-cause mortality is a comprehensive indicator of inequalities in health, attention to specific causes of death in future studies will shed light on the precise pathways through which SEP is linked to health. Notwithstanding these limitations, our study has a number of methodological strengths. First, to best of our knowledge, this is one of the first studies to examine the links between SEP and mortality using structural equation modeling. The use of a large sample and the structural equation modeling approach enabled us to distinguish between indirect and direct effects among multiple behavioral and biological variables, and to analyze relationships at the latent variable level, which reduces variance due to measurement errors and minimizes multi-colinearity.[39].

In conclusion, the present study expands previous literature on the impact of socioeconomic position on mortality by disentangling the underlying mechanisms in inequalities in health. Reducing socioeconomic disparities in mortality in the long term will require interventions that aim to reduce stress and promote behavioural changes, especially physical activity and smoking, among the socioeconomically disadvantaged groups. One important venue for future research would be to explore the impact of psychosocial resources such as perceived control which help combat negative consequences of stressors, on allostatic load and its mediating role on the relationship between socioeconomic status and health.

\section{Acknowledgments}

None.

\section{Conflicts of interest}


1 The authors have no conflicts of interest to declare.

2 Funding

3 The Korean Metabolic Syndrome Mortality Study is supported by the grant from the Korean

4 Health Technology R\&D Project, Ministry of Health \& Welfare, Republic of Korea (HI14C2686). 


\section{References}

1 Clark AM, DesMeules M, Luo W, et al. Socioeconomic status and cardiovascular disease: risks and implications for care. Nature Reviews Cardiology 2009;6:712-22.

2 Sommer I, Griebler U, Mahlknecht P, et al. Socioeconomic inequalities in noncommunicable diseases and their risk factors: an overview of systematic reviews. BMC public health 2015;15:1.

3 Khang $\mathrm{Y}-\mathrm{H}$, Kim HR. Explaining socioeconomic inequality in mortality among South Koreans: an examination of multiple pathways in a nationally representative longitudinal study. International Journal of Epidemiology 2005;34:630-7.

4 Vandenheede $\mathrm{H}$, Vikhireva $\mathrm{O}$, Pikhart $\mathrm{H}$, et al. Socioeconomic inequalities in all-cause mortality in the Czech Republic, Russia, Poland and Lithuania in the 2000s: findings from the HAPIEE Study. Journal of epidemiology and community health 2013:jech-2013-203057.

5 Skalická V, Van Lenthe F, Bambra C, et al. Material, psychosocial, behavioural and biomedical factors in the explanation of relative socio-economic inequalities in mortality: evidence from the HUNT study. International journal of epidemiology 2009:dyp262.

6 Siahpush M, English D, Powles J. The contribution of smoking to socioeconomic differentials in mortality: results from the Melbourne Collaborative Cohort Study, Australia. Journal of epidemiology and community health 2006;60:1077-9.

7 Stringhini S, Sabia S, Shipley $M$, et al. Association of socioeconomic position with health behaviors and mortality. Jama 2010;303:1159-66.

8 Goodman E, Daniels SR, Dolan LM. Socioeconomic disparities in insulin resistance: results from the Princeton School District Study. Psychosomatic medicine 2007;69:61-7.

9 Steptoe A, Kunz-Ebrecht $\mathrm{S}$, Owen $\mathrm{N}$, et al. Socioeconomic status and stress-related biological responses over the working day. Psychosomatic Medicine 2003;65:461-70.

10 Gimeno D, Brunner EJ, Lowe GD, et al. Adult socioeconomic position, C-reactive protein and interleukin-6 in the Whitehall II prospective study. European journal of epidemiology 2007;22:675-83.

11 Szanton SL, Gill JM, Allen JK. Allostatic load: a mechanism of socioeconomic health disparities? Biological Research for Nursing 2005;7:7-15.

12 Dowd JB, Goldman N. Do biomarkers of stress mediate the relation between socioeconomic status and health? . Journal of Epidemiology and Community Health 2006;60:633-9.

13 McEwen BS, Stellar E. Stress and the individual: mechanisms leading to disease. Archives of internal medicine 1993;153:2093-101.

14 Seeman TE, Crimmins $\mathrm{E}$, Huang $\mathrm{M}-\mathrm{H}$, et al. Cumulative biological risk and socio-economic differences in mortality: MacArthur studies of successful aging. Social science \& medicine 2004;58:1985-97. 
Glei DA, Goldman N, Shkolnikov VM, et al. To what extent do biomarkers account for the large social disparities in health in Moscow? Social Science \& Medicine 2013;77:164-72.

16 Song Y-M, Byeon JJ. Excess mortality from avoidable and non-avoidable causes in men of low socioeconomic status: a prospective study in Korea. Journal of epidemiology and community health 2000;54:166-72.

17 Mok Y, Jeon C, Lee GJ, et al. Physical Activity Level and Colorectal Cancer Mortality. Asia Pac J Public Health 2016;28:638-47.

18 Robertson T, Popham F, Benzeval M. Socioeconomic position across the lifecourse \& allostatic load: data from the West of Scotland Twenty-07 cohort study. BMC Public Health 2014;14:184.

19 Langelaan S, Schaufeli WB, van Doornen LJ, et al. Is burnout related to allostatic load? International journal of behavioral medicine 2007;14:213-21.

20 Bird CE, Seeman T, Escarce JJ, et al. Neighbourhood socioeconomic status and biological 'wear and tear' in a nationally representative sample of US adults. Journal of Epidemiology and Community Health 2010;64:860-5.

21 Seeman TE, Singer $\mathrm{BH}$, Rowe JW, et al. Price of adaptation-allostatic load and its health consequences: MacArthur studies of successful aging. Archives of internal medicine 1997;157:225968.

22 Juster R-P, McEwen BS, Lupien SJ. Allostatic load biomarkers of chronic stress and impact on health and cognition. Neuroscience \& Biobehavioral Reviews 2010;35:2-16.

23 Muthén LK, Muthén BO. Mplus (Version 7.4). Los Angeles, CA: Muthén \& Muthén 2012.

24 Asparouhov T, Masyn K, Muthen B. Continuous time survival in latent variable models. Proceedings of the Joint Statistical Meeting in Seattle 2006:180-7.

25 Demissie S, LaValley MP, Horton NJ, et al. Bias due to missing exposure data using complete-case analysis in the proportional hazards regression model. Stat Med 2003;22:545-57.

$26 \mathrm{Hu}$ LT, Bentler PM. Cutoff Criteria for Fit Indexes in Covariance Structure Analysis: Conventional Criteria Versus New Alternatives. Struct Equ Modeling 1999;6:1-55.

27 MacKinnon DP, Fairchild AJ, Fritz MS. Mediation analysis. Annual review of psychology 2007;58:593.

28 Vathesatogkit P, Batty GD, Woodward M. Socioeconomic disadvantage and disease-specific mortality in Asia: systematic review with meta-analysis of population-based cohort studies. Journal of epidemiology and community health 2014;68:375-83.

29 Khang $\mathrm{Y}-\mathrm{H}$, Kim H-R. Socioeconomic Inequality in mortality using 12-year follow-up data from nationally representative surveys in South Korea. International journal for equity in health 2016;15:1.

30 Gruenewald TL, Karlamangla AS, Hu P, et al. History of socioeconomic disadvantage and allostatic load in later life. Social science \& medicine 2012;74:75-83. 
31 Seeman TE, McEwen BS, Rowe JW, et al. Allostatic load as a marker of cumulative biological risk: MacArthur studies of successful aging. Proceedings of the National Academy of Sciences 2001;98:4770-5.

32 Karlamangla AS, Singer BH, Seeman TE. Reduction in allostatic load in older adults is associated with lower all-cause mortality risk: MacArthur studies of successful aging. Psychosomatic medicine 2006;68:500-7.

33 Hu P, Wagle N, Goldman N, et al. The associations between socioeconomic status, allostatic load and measures of health in older Taiwanese persons: Taiwan social environment and biomarkers of aging study. Journal of biosocial science 2007;39:545-56.

34 Goldman N, Turra CM, Glei DA, et al. Physiological dysregulation and changes in health in an older population. Experimental Gerontology 2006;41:862-70.

35 Darmon N, Drewnowski A. Does social class predict diet quality? The American journal of clinical nutrition 2008;87:1107-17.

36 Kiecolt-Glaser JK, McGuire L, Robles TF, et al. Emotions, morbidity, and mortality: New perspectives from psychoneuroimmunology. Annual Review of Psychology 2002;53:83-107.

37 Lantz PM, House JS, Mero RP, et al. Stress, life events, and socioeconomic disparities in health: Results from the Americans' changing lives study. J Health Soc Behav 2005;46:274-88.

38 Gallo LC, Bogart LM, Vranceanu AM, et al. Socioeconomic status, resources, psychological experiences, and emotional responses: A test of the reserve capacity model. J Pers Soc Psychol 2005;88:386-99.

39 Kline RB. Principles and practice of structural equation modeling: Guilford publications 2015. 


\section{Supplementary Material}

Table S1. Total, Direct and Indirect Effects of Socioeconomic Position on All-cause Mortality Mediated Through Allostatic Load and Health Behaviours Based on Complete Cases Analysis $(\mathrm{N}=15,653)$

\begin{tabular}{|c|c|c|c|}
\hline & Regression coefficient (S.E) & $\begin{array}{l}\text { Hazard ratio (95\% } \\
\text { confidence interval) }\end{array}$ & p-value \\
\hline \multicolumn{4}{|l|}{ Direct effect } \\
\hline $\mathrm{SEP} \rightarrow$ Mortality & $-0.279(0.037)$ & $0.757(0.711$ to 0.803$)$ & $P<0.001$ \\
\hline \multicolumn{4}{|l|}{ Indirect effects } \\
\hline $\mathrm{SEP} \rightarrow \mathrm{AL} \rightarrow$ Mortality & $-0.017(0.004)$ & 0.984 (0.976 to 0.991$)$ & $P<0.001$ \\
\hline $\mathrm{SEP} \rightarrow$ Non-smoking status $\rightarrow$ Mortality & $-0.025(0.004)$ & 0.976 (0.969 to 0.982$)$ & $P<0.001$ \\
\hline SEP $\rightarrow$ Physical exercise $\rightarrow$ Mortality & $-0.006(0.006)$ & 0.994 (0.984 to 1.004$)$ & $\mathrm{p}=0.349$ \\
\hline $\begin{array}{l}\text { Total effect of SEP on Mortality } \\
\text { (Sum of indirect effects and direct effect) }\end{array}$ & $-0.327(0.035)$ & 0.722 (0.681 to 0.764$)$ & $P<0.001$ \\
\hline \multicolumn{4}{|c|}{ Proportion of the effect of SES on Mortality that was: } \\
\hline Mediated by AL (\%) & 5.2 & & \\
\hline Mediated by non-smoking (\%) & 7.7 & & \\
\hline Mediated by physical exercise (\%) & 1.8 & & \\
\hline Total indirect effect (\%) & 14.7 & & \\
\hline Direct effect $(\%)$ & 85.3 & & \\
\hline
\end{tabular}

\footnotetext{
a Standard error

Note: $\mathrm{SEP}=$ Socioeconomic Position; $\mathrm{AL}=$ Allostatic load;
} 


\section{Figure legends}

Figure 1 Theoretical pathway linking SEP and health.

Figure 2 Structural Equation Model for the Relationship between Socioeconomic Position, Allostatic Load, Health Behaviours and All-Cause Mortality. 
Figure 1

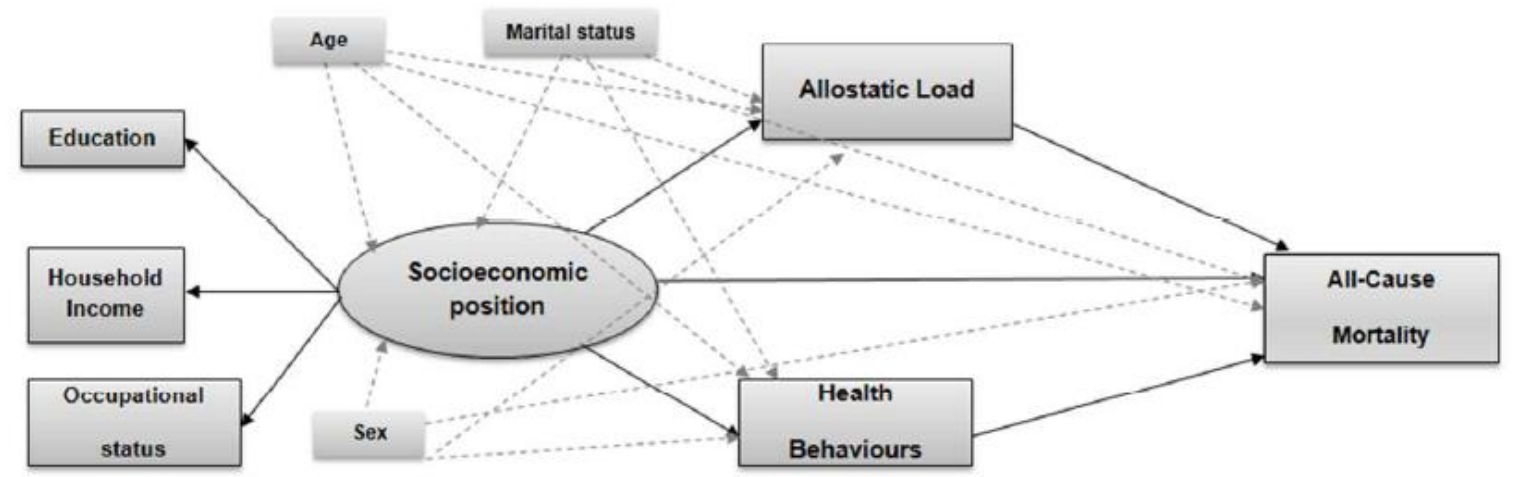


Figure 2

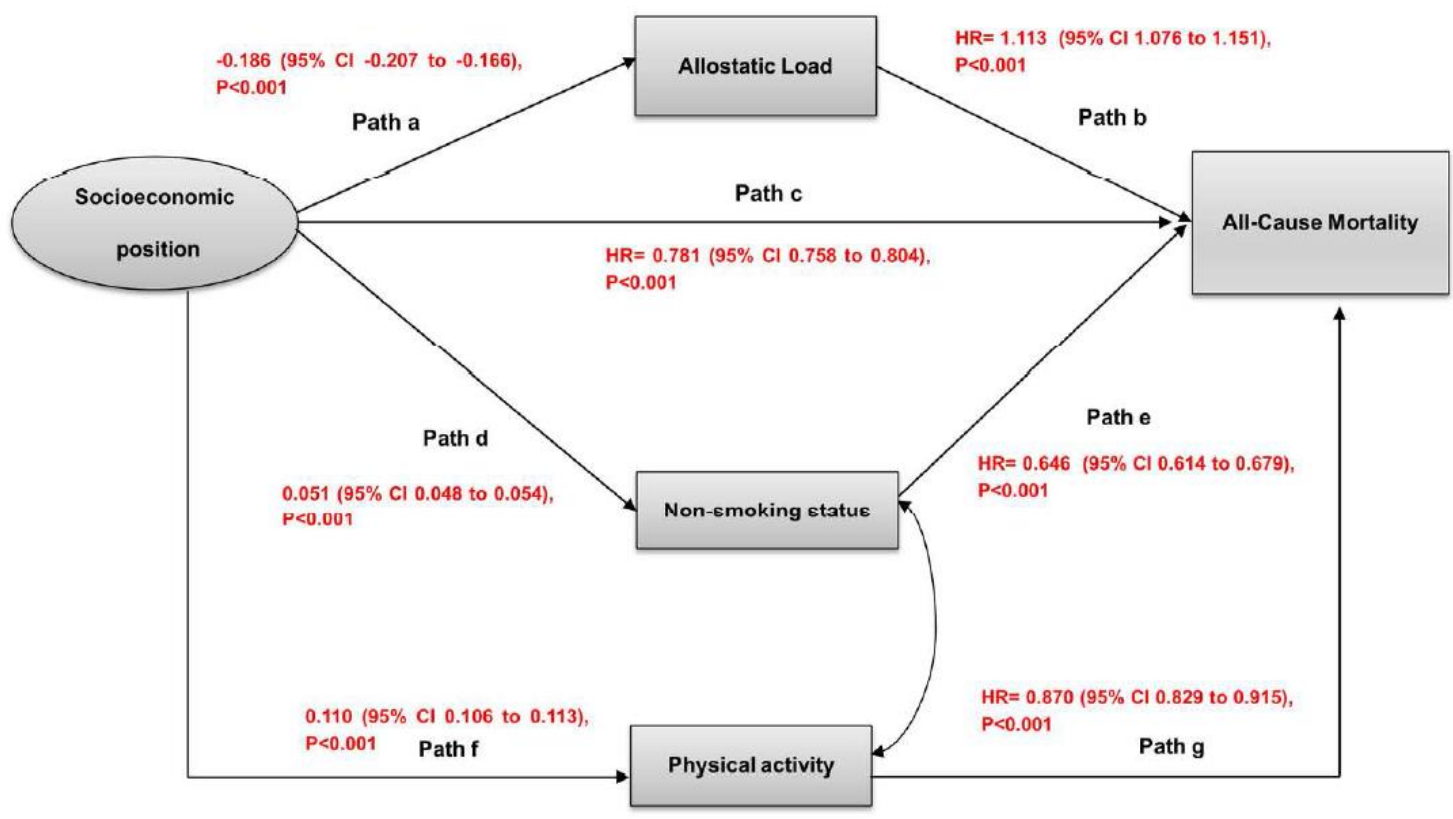

